\title{
RL71, a second-generation curcumin analog, induces apoptosis and downregulates Akt in ER-negative breast cancer cells
}

\author{
BABASAHEB YADAV $^{1}$, SEBASTIEN TAURIN ${ }^{1}$, LESLEY LARSEN $^{2}$ and RHONDA J. ROSENGREN ${ }^{1}$ \\ Departments of ${ }^{1}$ Pharmacology and Toxicology, ${ }^{2}$ Chemistry, University of Otago, Dunedin, New Zealand
}

Received February 14, 2012; Accepted April 30, 2012

DOI: $10.3892 /$ ijo.2012.1521

\begin{abstract}
There is a need for the development of new, safe and efficacious drug therapies for the treatment of estrogen receptor (ER)-negative breast cancers. RL71 is a second-generation curcumin analog that exhibits potent cytotoxicity towards a variety of ER-negative breast cancer cells. Therefore, we have further examined the mechanism of this anticancer activity in three different ER-negative breast cancer cell lines. The mechanistic studies demonstrated that RL71 $(1 \mu \mathrm{M})$ induced cell cycle arrest in the $\mathrm{G} 2 / \mathrm{M}$ phase of the cell cycle. Moreover, RL71 $(1 \mu \mathrm{M})$ caused $35 \%$ of SKBr3 cells to undergo apoptosis after $48 \mathrm{~h}$ and this effect was time-dependent. This correlated with an increase in cleaved caspase-3 as shown by western blotting. RL71 $(1 \mu \mathrm{M})$ also decreased HER2/neu phosphorylation and increased p27 in SKBr3 cells. While in MDA-MB-231 and MDA-MB-468 cells RL71 $(1 \mu \mathrm{M})$ significantly decreased Akt phosphorylation and transiently increased the stress kinases JNK1/2 and p38 MAPK. In addition, RL71 exhibited anti-angiogenic potential in vitro as it inhibited HUVEC cell migration and the ability of these cells to form tube-like networks. RL71 $(8.5 \mathrm{mg} / \mathrm{kg})$ was also orally bioavailable as it produced a peak plasma concentration of $0.405 \mu \mathrm{g} / \mathrm{ml}, 5 \mathrm{~min}$ after oral drug administration. Thus, our findings provide evidence that RL71 has potent anticancer activity and has potential to be further developed as a drug for the treatment of ER-negative breast cancer.
\end{abstract}

\section{Introduction}

Breast cancer is the most prevalent form of cancer diagnosed in women, and there continues to be limited drug treatment options for the $\sim 30 \%$ of patients whose cancer lacks the estrogen receptor (ER) $(1,2)$. ER-negative breast cancer can either express the human epidermal growth factor receptor 2 (Her2, erbb2) or lack this receptor. Triple negative breast

Correspondence to: Dr Rhonda J. Rosengren, Department of Pharmacology and Toxicology, 18 Frederick St, University of Otago, Dunedin 9016, New Zealand

E-mail: rhonda.rosengren@otago.ac.nz

Key words: triple negative breast cancer, apoptosis, angiogenesis cancer (TNBC) is defined by a lack of the expression of the ER, progesterone receptor and HER2. They account for $10-17 \%$ of all breast cancers and represent $85 \%$ of the basal-like subtype (3), one of the five subgroups of breast cancer categorized in recent years (4). TNBC has an aggressive clinical behavior and is generally associated with poor prognosis, thus chemotherapy remains the only systemic treatment option available for these patients (5).

In the search for effective drugs for ER-negative breast cancer, several lead compounds from natural products such as curcumin (diferuloylmethane), the primary bioactive compound isolated from the rhizome of turmeric (Curcuma longa Linn.), have emerged. Curcumin has numerous pharmacological, chemopreventative and chemotherapeutic actions, and in vivo studies have demonstrated decreased tumorigenesis of many organs, including the mammary gland (6-11). In vitro studies have also demonstrated that curcumin exhibits potent cytoxicity toward numerous cell lines including ER-negative human breast cancer cells (12-18). However, curcumin has shown limited clinical efficacy, due to its low bioavailability and low stability in physiological media (7). Therefore, research groups have concentrated on the synthesis and characterization of curcumin analogs. Cyclohexanone analogs of curcumin as a group have shown enhanced activity and stability in biological medium compared to curcumin (19). Specifically, the cyclohexanone derivative 2,6-bis((3-methoxy-4-hydroxyphenyl)methylene)cyclohexanone (BMHPC) was cytotoxic towards ER-negative breast cancer cells ( $\mathrm{IC}_{50}$ of $\left.5.0 \mu \mathrm{M}\right)(20)$, although bioavailability and in vivo efficacy were still problematic. More recently fluorinated cyclohexanone derivatives have not only shown potent cytotoxicity toward MDA-MB-231 cells $\left(\mathrm{IC}_{50}\right.$ value of $\left.0.8 \mu \mathrm{M}\right)$ $(21,22)$, but also induced cell cycle arrest and apoptosis in both breast and prostate cancer cells (22).

Our laboratory has been involved in the search for new drug treatments for ER-negative breast cancer and uses the aggressive triple negative MDA-MB-231 human breast cancer cells, amongst others, to identify new potent drugs. Recently we have performed structure activity relationships to determine the cytotoxic potency of 2 nd generation heterocyclic cyclohexanone curcumin analogs. This study demonstrated that 3,5-bis(3,4,5-trimethoxybenzylidene)-1-methylpiperidine4-one (RL71)(Fig. 1) showed the lowest $\mathrm{IC}_{50}$ value $(0.3 \mu \mathrm{M})$ toward MDA-MB-231 and MDA-MB-468 breast cancer cells (23). It also elicited the strongest apoptotic response, as $\sim 40 \%$ of MDA-MB-231 cells underwent apoptosis $18 \mathrm{~h}$ following 
RL71 treatment ( $1 \mu \mathrm{M})(23)$. Therefore, this study was designed to comprehensively investigate the in vitro activity of this lead compound in various ER-negative breast cancer cell lines in order to determine its potential to be developed into a drug for aggressive breast cancer that lacks the ER.

\section{Materials and methods}

Materials. HUVEC, MDA-MB-231, MDA-MB-468 and SKBr3 cells were purchased from American Type Culture Collection (Manassas, VA). Primary antibodies to p38, pp38, NF- $\mathrm{kB}$, JNK, pJNK, cleaved caspase-3, 4EBP1, p4EBP1, p27, mTOR, pmTOR, HER2, pHER2 and $\beta$-actin were purchased from Cell Signaling Technology (Danvers, MA). Akt and pAkt primary antibodies were purchased from BD Biosciences (Auckland, NZ). Dulbecco's modified Eagle's medium (DMEM) nutrient mixture Ham's F-12, sulforhodamine B salt, propidium iodide (PI), ammonium persulfate, horseradish peroxidase were purchased from Sigma Aldrich (Auckland, NZ). Acrylamide, bisacrylamide, sodium dodecylsulfate and PVDF membrane were purchased from Bio-Rad Laboratories (Hercules, CA). Complete mini EDTA-free protease inhibitor cocktail and Annexin-V-FLUOS were purchased from Roche Diagnostics Corporation (Mannheim, Germany). RL71 was prepared as described previously (18). All other chemicals were of the highest purity commercially available.

Cell maintenance. MDA-MB-231, MDA-MB-468 and SkBr3 cells were maintained in complete growth media composed of DMEM/Ham's F12 supplemented with 5\% fetal bovine serum, $2 \mathrm{mM}$ L-glutamine, 100 units $/ \mathrm{ml}$ streptomycin, $250 \mathrm{ng} / \mathrm{ml}$ amphotericin $\mathrm{B}$, and 100 units $/ \mathrm{ml}$ penicillin and $2.2 \mathrm{~g} / 1$ $\mathrm{NaHCO}_{3}$.

Cytotoxicity. MDA-MB-231, MDA-MB-468 and SKBr3 cells $\left(95 \times 10^{4}\right.$ cells/well) were seeded in 12-well plates in $1 \mathrm{ml}$ DMEM/HamF12 supplemented with 5\% FBS, $100 \mathrm{U} / \mathrm{ml}$ penicillin, $100 \mu \mathrm{g} / \mathrm{ml}$ streptomycin, $25 \mathrm{ng} / \mathrm{ml}$ amphotericin B and $2.2 \mathrm{~g} / 1 \mathrm{NaHCO}_{3}$ and incubated for $24 \mathrm{~h}$ at $37^{\circ} \mathrm{C}$. For time course study, cells were treated with RL71 $(1 \mu \mathrm{M})$ for $6,12,24,36,48$ and $72 \mathrm{~h}$. Vehicle control cells were treated with DMSO (0.1\%). Cell number in each well was determined using the sulforhodamine B (SRB) assay (24).

Cell cycle analysis. Flow cytometry was used to analyze DNA content in order to determine cell cycle distribution. MDA-MB231, MDA-MB-468 and SKBr3 cells were plated and treated with RL71 $(1 \mu \mathrm{M})$ or $0.1 \%$ DMSO as control for 6-48 $\mathrm{h}$ in 6-well plates. The cells were harvested, washed with PBS and then fixed in $70 \%$ ethanol. Following rehydration with PBS, the cells were stained with PI in the dark at $4^{\circ} \mathrm{C}$ as described (25). The samples were analyzed via flow cytometry using a FACScaliber flow cytometer (Becton-Dickinson). The percentage of cells in each phase of cell cycle was determined using Cell Quest Pro software. Results are expressed as percent of cells in each phase of the cell cycle.

Induction of apoptosis. MDA-MB-468, and SKBr3 cells were seeded in 6-well culture plate in $2 \mathrm{ml}$ of DMEM/HamF12 supplemented with 5\% FBS, $100 \mathrm{U} / \mathrm{ml}$ penicillin, $100 \mu 1 / \mathrm{ml}$ streptomycin, $25 \mathrm{ng} / \mathrm{ml}$ amphotericin $\mathrm{B}$ and $2.2 \mathrm{~g} / 1 \mathrm{NaHCO}_{3}$. The cells were treated with RL71 $(1 \mu \mathrm{M})$ or vehicle control for 12-48 h. Apoptosis was assessed using Annexin-V-FLUCOS/ PI staining, as described (26). The samples were analyzed using a FACScaliber flow cytometer (Becton-Dickinson) and the proportion of apoptotic cells was determined using CellQuest Pro software.

Preparation of cell lysates. MDA-MB-231, MDA-MB-468 and $\mathrm{SKBr} 3$ cells were seeded in $10 \mathrm{~cm}$ culture dishes at $2.5 \times 10^{6} \mathrm{cells}$ per well in $10 \mathrm{ml}$ of DMEM/HamF12 supplemented with 5\% FBS, $100 \mathrm{U} / \mathrm{ml}$ penicillin, $100 \mu \mathrm{g} / \mathrm{ml}$ streptomycin, $25 \mathrm{ng} / \mathrm{ml}$ amphotericin $\mathrm{B}$ and $2.2 \mathrm{~g} / 1 \mathrm{NaHCO}_{3}$. Cells were treated with RL71 $(1 \mu \mathrm{M})$ or vehicle control for 0-36 h. At the end of treatment, whole cell lysates were prepared and protein concentration of the lysates was determined using the bicinchoninic acid (BCA) method (25).

Western blot analysis. Cell lysates were resolved by SDS-PAGE (40 $\mu \mathrm{g}$ protein per well) and then the proteins were transferred to a PVDF membrane. Protein levels were analyzed with the desired primary antibodies, followed by horseradish peroxidase-conjugated secondary antibodies (Bio-Rad). The digital chemiluminescence images were taken by a Versadoc densitometer (Bio-Rad).

Transwell migration. Transwell migration was performed using 24 well plates containing BioCoat ${ }^{\mathrm{TM}}$ Matrigel $^{\mathrm{TM}}$ Invasion Chamber inserts (BD Biosciences, Bedford, MA). HUVEC cells $(50,000 /$ well $)$ were plated on rehydrated Matrigel coated culture inserts. The bottom chamber contained $500 \mu \mathrm{l}$ of EGM serum free media. The cells were treated with 0.1\% DMSO or RL71 $(1 \mu \mathrm{M})$ and incubated for $18 \mathrm{~h}$ at $37^{\circ} \mathrm{C}$ in a humidified $5 \% \mathrm{CO}_{2}$ incubator. After incubation, all contents from well inserts were aspirated and non-migrated cells were removed with a cotton swab. Migrated cells on the bottom of the filters were stained with DiffQuick solution for $1 \mathrm{~min}$ and excess stain was washed with water and dried. Cells on the filters were counted using a Zeiss Axioplan camera and compared to the control well insert that contained no Matrigel. Results are expressed as migrated cells as a percent of total cell population.

Endothelial tube formation. The day before performing the tube formation assay, a Matrigel matrix was incubated on ice overnight. On the day of the assay, $125 \mu$ l Geltrex Matrigel was transferred into wells of a 24-well plate. The plate was incubated at $37^{\circ} \mathrm{C}, 5 \% \mathrm{CO}_{2}$ for $30 \mathrm{~min}$. HUVEC cells $\left(5 \times 10^{4} /\right.$ well) were then loaded into each well, followed by addition of DMSO $(0.1 \%)$ or RL71 $(1 \mu \mathrm{M})$. The plate was incubated at $37^{\circ} \mathrm{C}, 5 \% \mathrm{CO}_{2}$ for $18 \mathrm{~h}$ and photographs (200x) were taken by an individual blinded to the treatment groups.

Animals and housing. Female CD-1 mice (6-weeks old) were purchased from the Hercus Taieri Resource Unit (Dunedin, NZ). All procedures were approved by the University of Otago (AEC\# 91/07). Mice were housed in pathogen-free conditions with woodchip bedding with access to food (Reliance rodent diet, Dunedin, NZ) and water ad libitum. Mice were housed in a $21-24^{\circ} \mathrm{C}$ environment on a scheduled $12 \mathrm{~h}$ light/dark cycle and acclimatized for 3 days prior to experimentation. 
<smiles>COc1cc(/C=C2\CN(C)C/C(=C\c3cc(OC)c(OC)c(OC)c3)C2=O)cc(OC)c1OC</smiles>

Figure 1. Chemical structure of RL71.

\section{A MDA-MB-231}

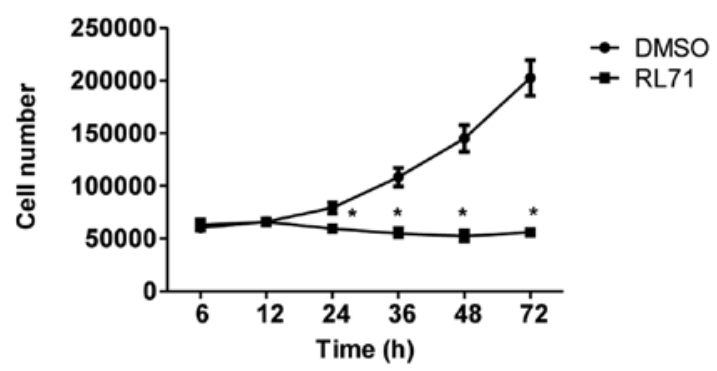

B MDA-MB-468

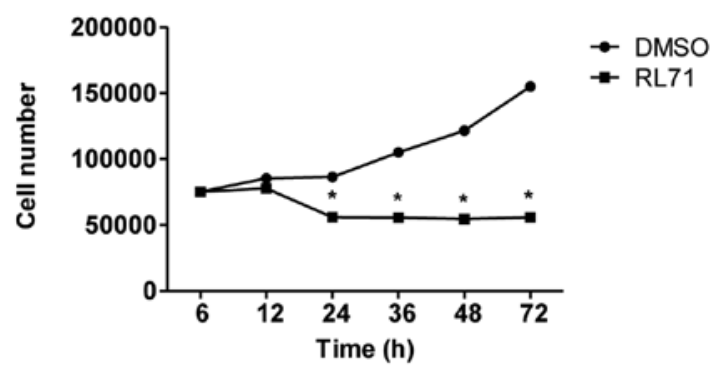

C SKBr3

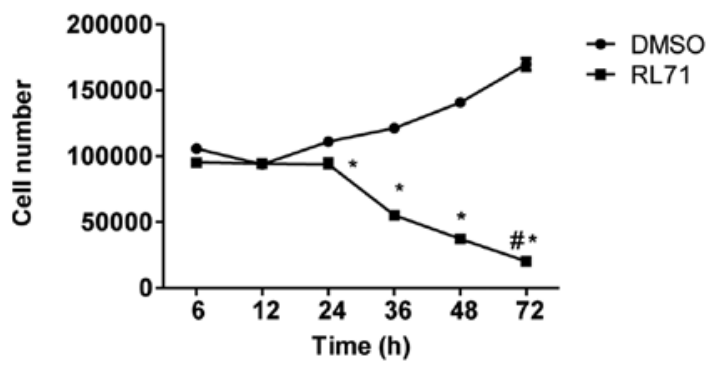

Figure 2. Time-course cytotoxicity of RL71 in (A) MDA-MB-231, (B) MDAMB-468, and (C) SKBr3 cells. Cells were treated with either RL71 $(1 \mu \mathrm{M})$ or DMSO $(0.1 \%)$ for 6-72 h. Cell number was determined using the SRB assay. Each symbol represents the mean \pm SEM of 3 independent experiments performed in triplicate. The data were analyzed using a two-way ANOVA coupled with a Bonferroni post-hoc test where asterisk indicates a statistically significant difference compared with the control group, $\mathrm{p}<0.001 .{ }^{\text {"SStatistically }}$ significant difference compared with all previous time points, $\mathrm{p}<0.01$.

Oral bioavailability of RL71. Mice (3/group) were orally gavaged with RL71 and blood samples were collected at the following time points $0,5 \mathrm{~min}, 10 \mathrm{~min}, 15 \mathrm{~min}, 30 \mathrm{~min}, 1 \mathrm{~h}$, $1.5 \mathrm{~h}$ and $2 \mathrm{~h}$ ). Plasma was separated and stored at $-20^{\circ} \mathrm{C}$. The
A MDA-MB-231

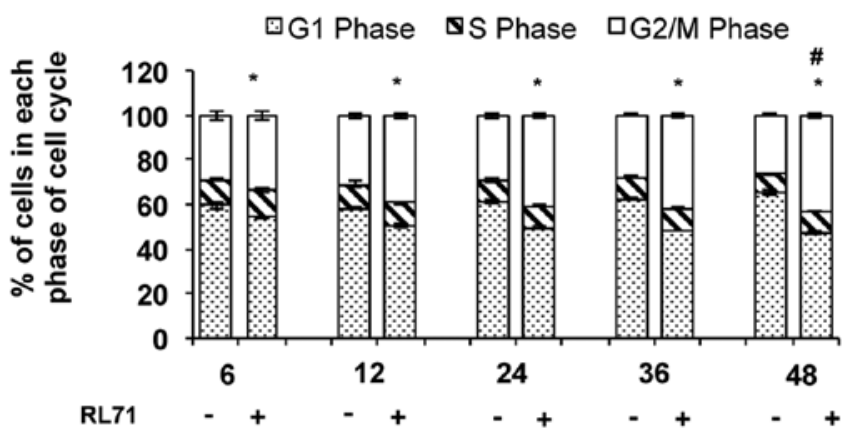

B MDA-MB-468

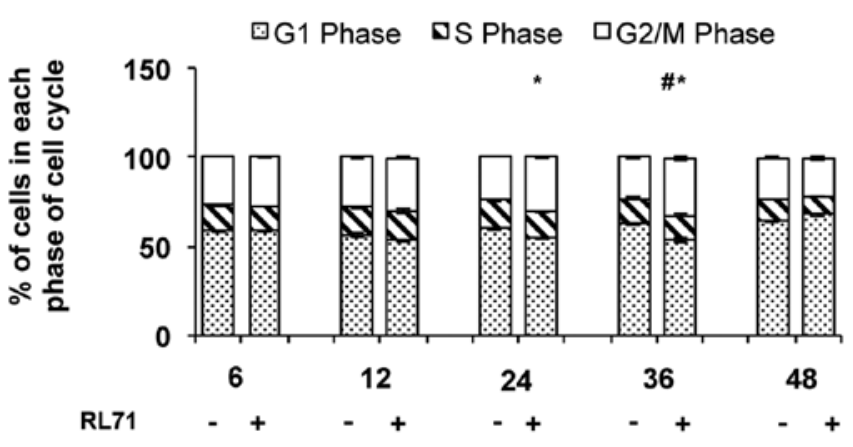

C SKBr3

๑G1 Phase $\Delta$ S Phase $\square \mathrm{G} 2 / \mathrm{M}$ Phase बSub G1

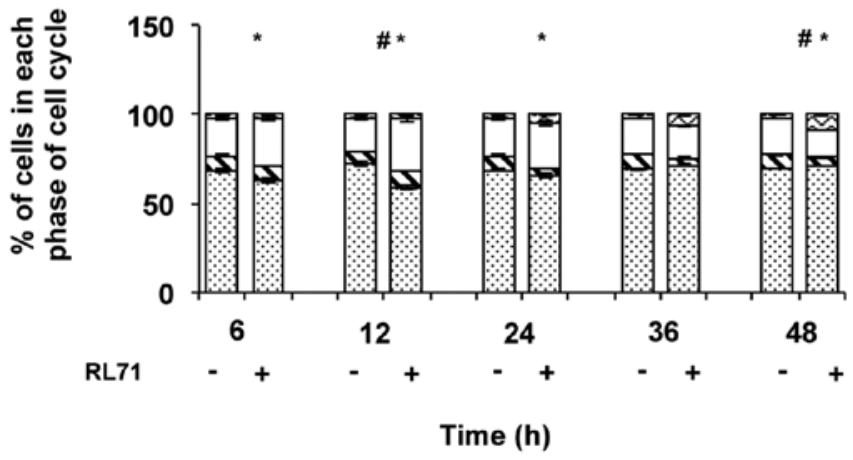

Figure 3. Cell cycle arrest following treatment of ER negative breast cancer cells with RL71 in (A) MDA-MB-231, (B) MDA-MB-468 and (C) SKBr3 cells. Cells were treated with RL71 $(1 \mu \mathrm{M})$ for 6, 12, 24, 36 and $48 \mathrm{~h}$. Vehicle control cells were treated with $0.1 \%$ DMSO. Propidium iodide staining and flow cytometry was used to determine the proportion of cells in the various phases of the cell cycle. Columns represent the mean proportion of cells in each phase of cell cycle (\% of total) \pm SEM of 3 independent experiments conducted in triplicate. Data were analyzed with a two-way ANOVA coupled with a Bonferroni post-hoc test. Asterisk indicates a statistically significant difference between treatment and control in the number of cells in the G2/M phase of the cell cycle, $\mathrm{p}<0.001$. "Statistically significant difference in the number of cells in the $\mathrm{G} 2 / \mathrm{M}$ phase of the cell cycle compared with all other time points, $\mathrm{p}<0.01$.

samples for analysis were prepared by addition of methanol to precipitate the proteins, followed by sonication and filtration. The samples were analyzed by HPLC with UV-DAD detection. HPLC analysis was performed using an Agilent HP1100 system at $25^{\circ} \mathrm{C}$ on a 18 column (Phenomenex Gemini-NX) $3 \mu(110 \mathrm{~A}, 150 \times 2 \mathrm{~mm})$ with a $2 \times 4 \mathrm{~mm} \mathrm{C18}$ guard column. RL71 was monitored $390 \mathrm{~nm}$. The mobile phase was acetonitrile 


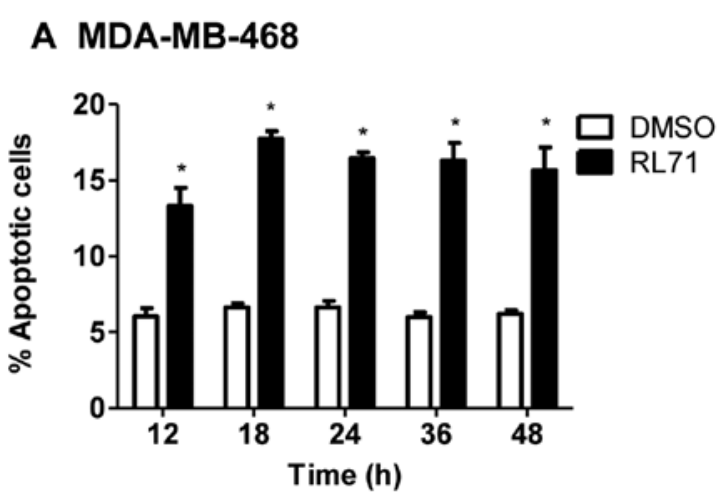

B SKBr3

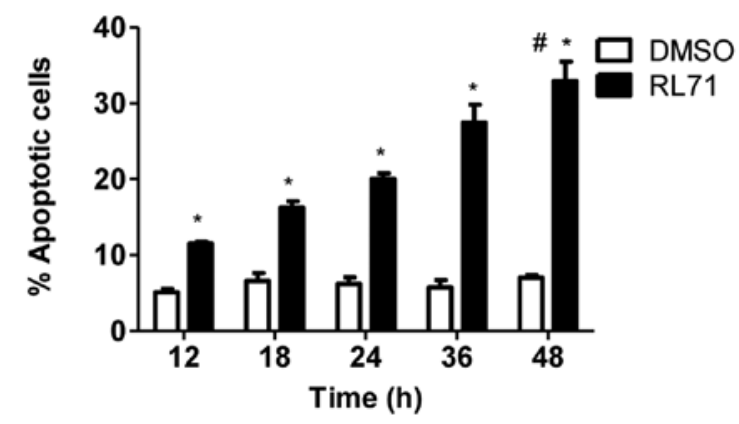

Figure 4. Induction of apoptosis following treatment of (A) MDA-MB-468 and (B) SKBr3 cells with RL71. Cells were treated with RL71 $(1 \mu \mathrm{M})$ for 12, 18, 24,36 and $48 \mathrm{~h}$. Vehicle control cells were treated with $0.1 \%$ DMSO. Values are expressed as mean number of apoptotic cells as a percentage of the total population \pm SEM from 3 independent experiments conducted in triplicate. Data were analyzed using a two-way ANOVA coupled with a Bonferroni posthoc test. Asterisk indicates a statistically significant difference compared with the control group, $\mathrm{p}<0.001 .{ }^{\text {" S}}$ Statistically significant difference compared with all previous time points, $\mathrm{p}<0.01$.

in water with $0.1 \%$ formic acid: $\mathrm{t}_{0}=30 \%, \mathrm{t}_{10}=70 \%, \mathrm{t}_{15}=100 \%$, $\mathrm{t}_{17}=30 \%, \mathrm{t}_{20}=30 \%$. The flow rate was $0.3 \mathrm{ml} / \mathrm{min}$, with an injection volume of $5 \mu \mathrm{l}$.

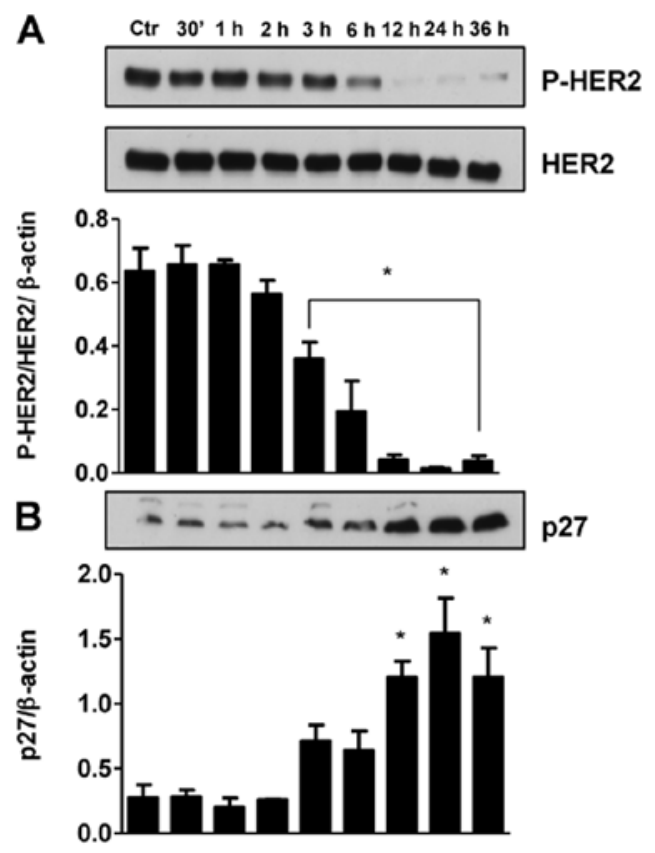

Statistical analysis. When time was a factor data were analyzed using a two-way ANOVA coupled with a Bonferroni post-hoc test. Data that did not have time as a facor were analysed using a one-way ANOVA coupled with a Bonferroni post-hoc test. Transwell migration data were analyzed by a Student's t-test. $\mathrm{p}<0.05$ was the minimal requirement for a statistically significant difference.

\section{Results}

Previously we have shown that treatment for 5 days with RL71 elicited sub micromolar $\mathrm{IC}_{50}$ values in three different ER-negative breast cancer cell lines (20). Therefore, the first aim of this study was to examine the cytotoxicity of RL71 toward MDA-MB-231, MDA-MB-468 and SKBr3 cells over a time-course. The results showed that RL71 $(1 \mu \mathrm{M})$ elicited timedependent and cell line-dependent cytotoxicity. Specifically, time-dependent cytotoxicity was elicited in SKBr3 cells with significantly increased cytotoxicity at $72 \mathrm{~h}$ compared with all other time points (Fig. 2). However, in the two triple negative breast cancer (TNBC) cell lines no further cytotoxicity was elicited after $24 \mathrm{~h}$. Thus, RL71 showed potent cytotoxicity toward SKBr3 cells compared to a cytostatic effect in TNBC cells.

We next examined whether the cytotoxicity of RL71 was due to G2/M phase cell cycle arrest. Treatment of MDA-MB231, MDA-MB-468, and SKBr3 cells with RL71 (1 $\mu \mathrm{M})$ produced $\mathrm{G} 2 / \mathrm{M}$ phase arrest in all three cell lines. Specifically, at $48 \mathrm{~h}$, RL71 caused an $162 \%$ increase in the proportion of MDA-MB-231 cells in G2/M phase over control (Fig. 3A), while in MDA-MB-468 cells, the proportion of cells in G2/M phase increased by $140 \%$ over control at $36 \mathrm{~h}$ (Fig. 3B). In SKBr3 cells, after $12 \mathrm{~h}$, the proportion of cells undergoing $\mathrm{G} 2 / \mathrm{M}$ phase was increased by $153 \%$ over control (Fig. 3C). Moreover, there was a significant reduction in the proportion of cells in $\mathrm{S}$ phase at 24,36 and $48 \mathrm{~h}$. SKBr3 cells were the only cell type to show an increase in subG1 cells. The effect in MDA-MB-231 cells was time-dependent as the number of cells undergoing G2/M

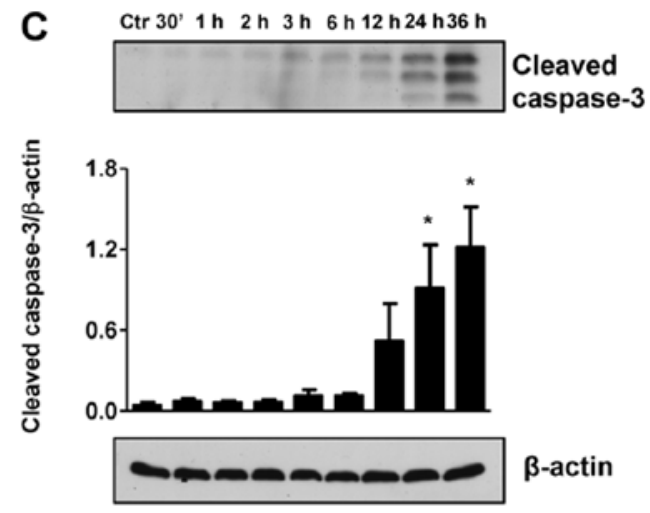

Figure 5. RL71 downregulates HER2/neu in SKBr3 cells. SKBr3 cells were seeded in $10 \mathrm{~cm}$ culture dishes at $2.5 \times 10^{6}$ cells per well and were treated with RL71 $(1 \mu \mathrm{M})$ or control (0.1\% DMSO) for the indicated time. Cell lysates were then prepared, and the expression of (A) HER2 and pHER2, (B) p27 and (C) cleaved caspase- 3 were examined using western immunoblotting. Bars represent the mean \pm SEM from 3 independent experiments. Representative blots are shown above each bar graph. Data were analyzed using a two-way ANOVA coupled with a Bonferroni post-hoc test. Asterisk indicates significantly different from control, $\mathrm{p}<0.05$. 
A
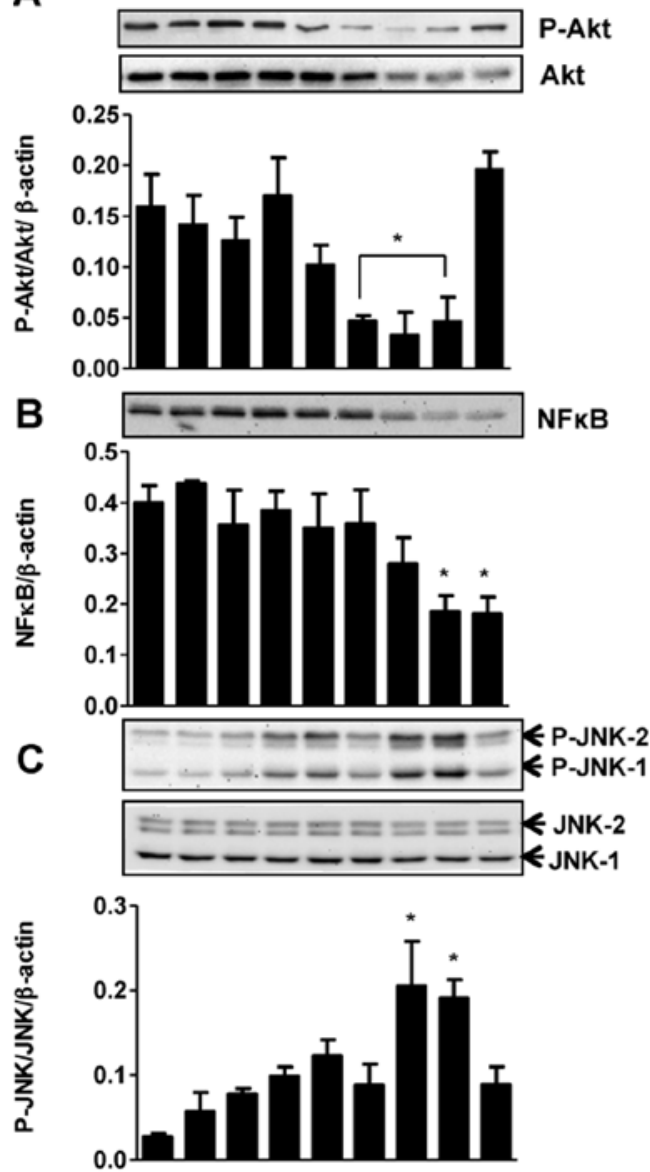

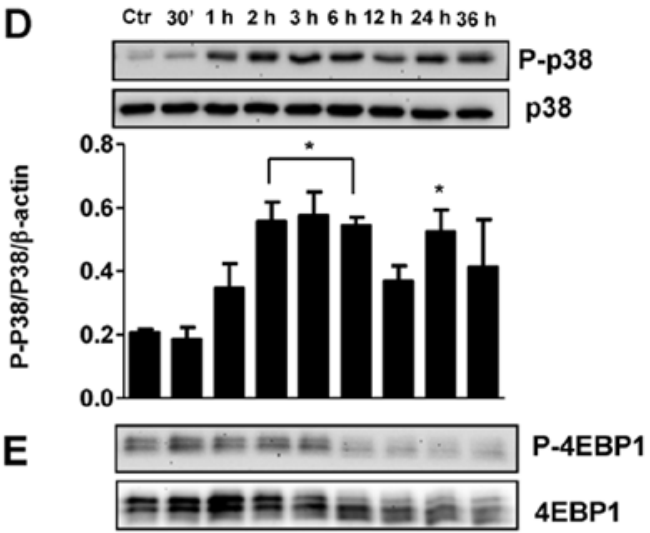

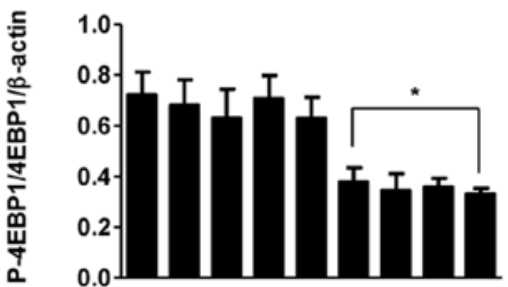
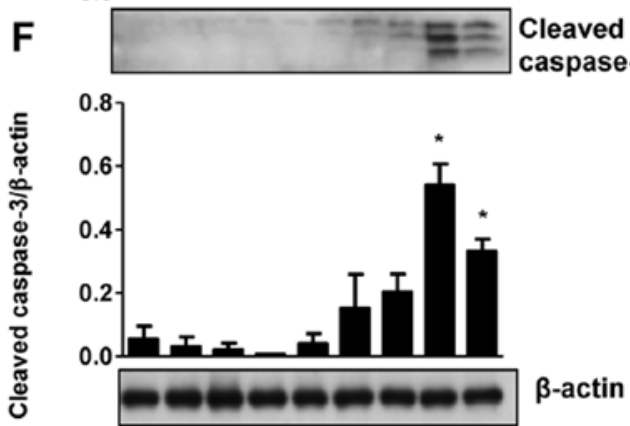

Figure 6. RL71 modulates cell signaling proteins in MDA-MB-231 cells. MDA-MB-231 cells were seeded in $10 \mathrm{~cm}$ culture dishes at $2.5 \times 10^{6}$ cells per well and were treated with RL71 $(1 \mu \mathrm{M})$ or control $(0.1 \%$ DMSO) for the indicated time. Cell lysates were then prepared, and the expression of (A) Akt and pAkt, (B) NF- $\kappa \mathrm{B}$, (C) JNK1/2 and pJNK1/2, (D) p38 and pp38, (E) 4EBP1 and p4EBP1 and (F) cleaved caspase-3 were examined using western immunoblotting. Bars represent the mean \pm SEM from 3 independent experiments. Representative blots are shown above each bar graph. Data were analyzed using a two-way ANOVA coupled with a Bonferroni post-hoc test. Asterisk indicates significantly different from control, $\mathrm{p}<0.05$.

phase arrest was signficantly increased at $48 \mathrm{~h}$ compared to all other time points.

To determine if cell cycle arrest drives apoptosis, timedependent changes in apoptosis were examined. RL71 $(1 \mu \mathrm{M})$ induced apoptosis in MDA-MB-468 and SKBr3 cells (Fig. 4). The effect was time-dependent in $\mathrm{SkBr} 3$ cells, as $35 \%$ of cells were apoptotic after $48 \mathrm{~h}$ and this was significantly elevated compared to all other time points (Fig. 4B). In contrast 14-18\% of MDA-MB-468 cells underwent apoptosis and this effect was maintained from 12-48 h (Fig. 4A) indicating the lack of a time-dependent effect. G2/M arrest did not drive apoptosis in MDA-MB-468 cells, as apoptosis was increased at $12 \mathrm{~h}$, which was prior to the increase in $\mathrm{G} 2 / \mathrm{M}$ phase arrest. However, the early appearance of G2/M phase arrest at $12 \mathrm{~h}$ in SKBr3 cells is a likely reason why these cells show a strong apoptotic response over time. Additionally, our previous work with RL71 in MDA-MB-231 cells indicated that the induction of apoptosis was strongest in this cell line, as $43 \%$ of cells underwent apoptosis and this effect was maintained from $18-36 \mathrm{~h}$ (23). Thus, the time-dependent increase in G2/M phase arrest leads to the sustained apoptotic effect. It is clear that overall
RL71 displayed a more potent cytotoxic effect in SKBr3 cells. To determine if this was due to the inhibition of HER2/neu expression, changes in cell signaling proteins were determined via western blotting.

HER2/neu expression was assessed in SKBr3 cells to determine the role of this protein in the cytotoxic actions of RL71. Treatment of SKBr3 cells with RL71 $(1 \mu \mathrm{M})$ decreased the ratio of pHER2/HER2 in a time-dependent manner, with an almost complete inhibition following $12 \mathrm{~h}$ (Fig. 5A). To link the changes in HER2/neu with cell cycle progression protein changes in the cyclin dependent kinase inhibitor, p27 were determined. The results showed that that decrease in HER2/neu correlated with a significant increase in the expression of p27 (Fig. 5B). Thus the decrease in HER2/neu leads to an increase in p27 leading to the observed G2/M arrest and apoptosis. The presence of apoptosis was also confirmed in SKBr3 cells by the signficant increase in cleaved caspase-3 (Fig. 5C).

To determine the molecular mechanisms responsible for apoptosis and cell cycle arrest in TNBC cells we first examined other isoforms of the EGFR in these cells. RL71 $(1 \mu \mathrm{M})$ failed to alter the ratio of $\mathrm{pEGFR/EGFR} \mathrm{protein} \mathrm{levels} \mathrm{(data} \mathrm{not}$ 
A
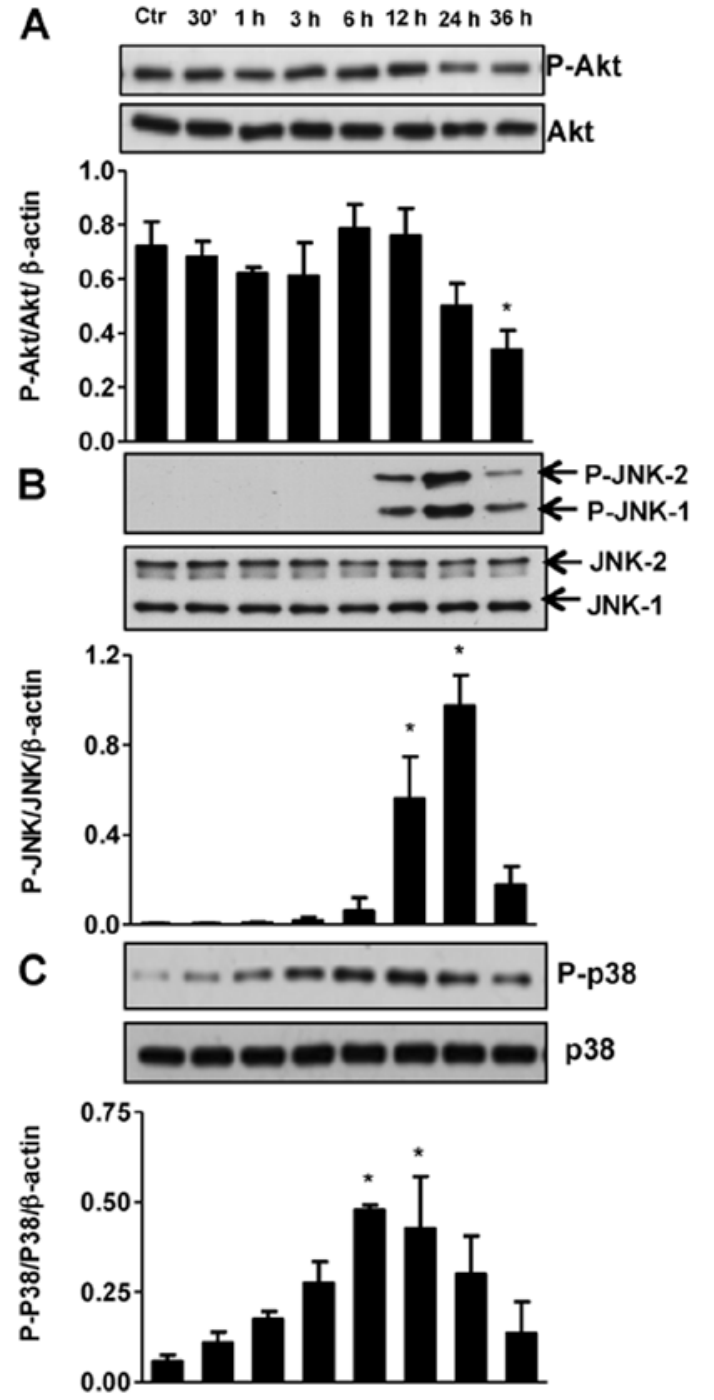
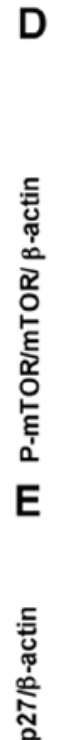

Ctr 30' $1 \mathrm{~h} 3 \mathrm{~h} 6 \mathrm{~h} 12 \mathrm{~h} 24 \mathrm{~h} 36 \mathrm{~h}$
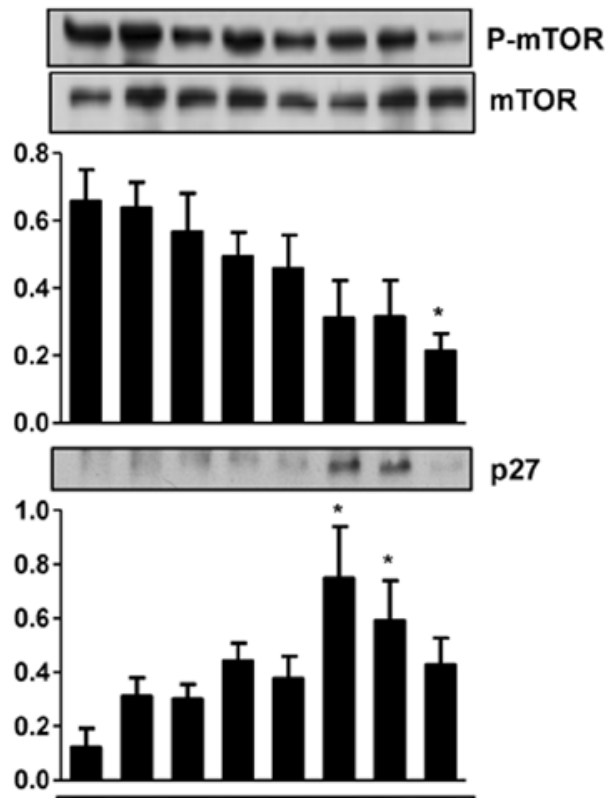

$\mathbf{F}$

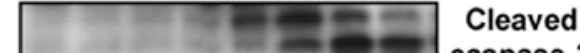

caspase-3

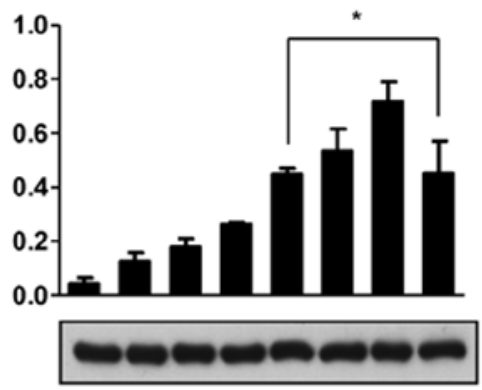

$\beta$-actin

Figure 7. RL71 modulates cell signaling proteins in MDA-MB-468 cells. MDA-MB-468 cells were seeded in $10 \mathrm{~cm}$ culture dishes at $2.5 \times 10^{6}$ cells per well and were treated with RL71 (1 $\mu \mathrm{M})$ or control (0.1\% DMSO) for the indicated time. Cell lysates were then prepared, and the expression of (A) Akt and pAkt, (B) JNK1/2 and pJNK1/2, (C) p38 and pp38, (D) mTOR and pmTOR, (E) p27 and (F) cleaved caspase-3 were examined using western immunoblotting. Bars represent the mean \pm SEM from 3 independent experiments. Representative blots are shown above each bar graph. Data were analyzed using a two-way ANOVA coupled with a Bonferroni post-hoc test. Asterisk indicates significantly different from control, $\mathrm{p}<0.05$.

shown). However, RL71 did modulate the expression of Akt, JNK1/2, p38 and caspase-3 in MDA-MB-231 and MDA-MB468 cells and differentially expressed NF- $\mathrm{BB}$, mTOR, 4EBP1 and p27. Specifically, RL71 significantly decreased the ratio of pAkt/Akt from 6-24 h in MDA-MB-231 cells and at $36 \mathrm{~h}$ in MDA-MB-468 cells (Fig. 6A and 7A). The stress initiated by the treatment of MDA-MB-231 and MDA-MB-468 cells resulted in a transient increase in both $\mathrm{JNK} 1 / 2$ and $\mathrm{p} 38$ MAPK phosphorylation (Fig. 6C and D and Fig. 7B and C). Furthermore, RL71 increased levels of cleaved caspase- 3 in a time-dependent manner and this effect was strongest in MDA-MD-468 cells with a significant increase occuring as early as $6 \mathrm{~h}$ (Fig. 6F and 7F). MDA-MB-231 cells were the only cell line to show a signficant decrease in NF- $\kappa \mathrm{B}$ and the ratio of p4EBP1/4EBP1 following RL71 (Fig. 6B and E), while the ratio of $\mathrm{pmTOR} / \mathrm{mTOR}$ was signficantly decreased and p27 was signficantly increased by RL71 in MDA-MB-468 cells (Fig. 7D and E).
To determine if RL71 could modulate angiogenesis, in vitro assays using HUVEC cells were performed, as the ability of these cells to migrate through Matrigel and form tube-like networks are hallmarks of angiogenesis. We used both quantifiable and visual assys to form a more complete in vitro picture. The results showed that RL71 $(1 \mu \mathrm{M})$ significantly reduced HUVEC cell migration by $46 \%$ compared to vehicle control (Fig. 8A) and completely inhibited endothelial tube formation after $18 \mathrm{~h}$ (Fig. 8B).

To confirm that RL71 was a new analog that showed improved oral bioavailability, female CD-1 mice were orally gavaged with a single dose of RL71 $(8.5 \mathrm{mg} / \mathrm{kg})$ and the resulting plasma concentration was determine by HPLC analysis. The results showed a peak plasma concentration of $0.405 \mu \mathrm{g} / \mathrm{ml}$, 5 min after oral drug administration. The plasma concentration of RL71 decreased in a time-dependent manner, as $0.15 \mu \mathrm{g} / \mathrm{ml}$ was present after $1 \mathrm{~h}$ and by $2 \mathrm{~h}$ the plasma concentration was at the limit of detection. 

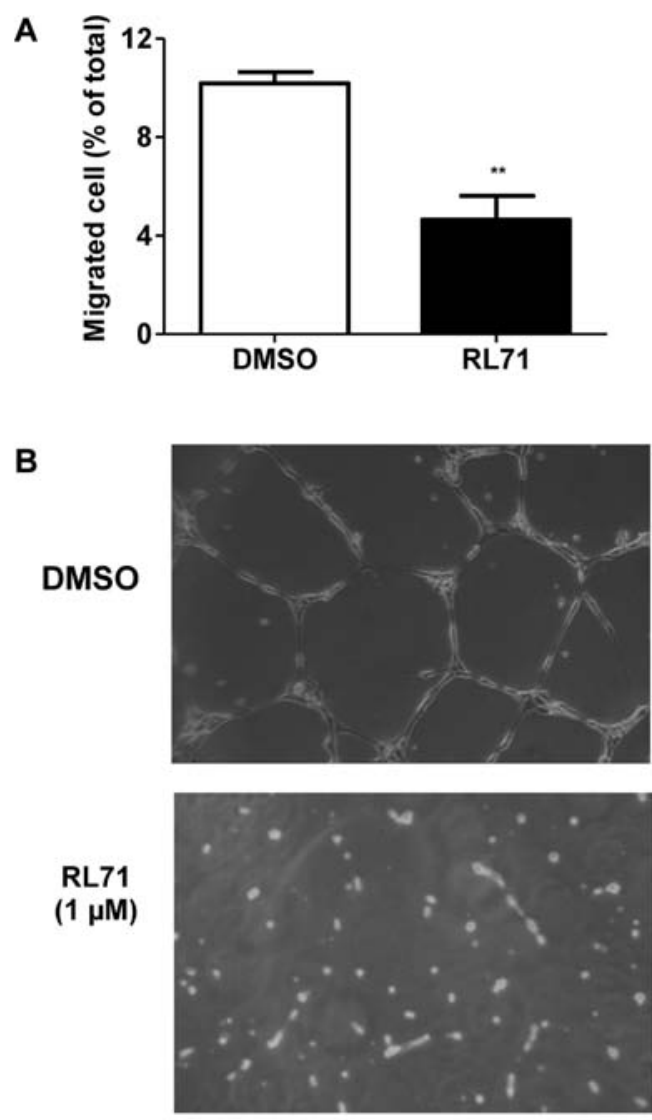

Figure 8. RL71 decreases HUVEC cell migration and tube formation. (A) HUVEC cells $(25,000 /$ well $)$ were seeded and treated with either DMSO $(0.1 \%)$ or RL71 $(1 \mu \mathrm{M})$ for $18 \mathrm{~h}$. Migrated cells were stained and counted. Bars represent mean \pm SEM of 3 independent experiments performed in triplicate. "Significantly different compared to control, $\mathrm{p}<0.01$, as determined from a Student's t-test. (B) HUVEC cells $(50,000 /$ well) were seeded and treated with DMSO $(0.1 \%)$ or RL71 $(1 \mu \mathrm{M})$ for $18 \mathrm{~h}$. Photographs were then taken by an examiner blinded to the treatment groups. Representative photograps from an experiment performed in quadruplicate are shown.

\section{Discussion}

We have previously shown that RL71 elicited the most potent cytotoxicity towards ER-negative breast cancer cells compared to all of our previously examined second generation curcumin derivatives (23). Therefore, this study was designed to further characterize this cytotoxic effect in vitro in a range of ER-negative breast cancer cell lines. The data presented show that RL71 promoted G2/M cell cycle arrest, induced apoptosis and modulated the Akt-dependent signaling pathway and stress response MAPK pathway. RL71 also downregulated the expression of HER2/neu in SKBr3 cells. In addition, RL71 exhibited anti-angiogenic effects in vitro by inhibiting the invasion of HUVEC cells and their ability to form endothelial tube like network. Importantly, RL71 is also orally bioavailable.

Breast cancer patients whose tumors overexpress HER2/ neu have a poor prognosis, shorter relapse time and shorter survival time (27). In this study we showed that RL71 inhibited HER2/neu expression in SKBr3 cells and this correlated with a concominant increase in p27 and cleaved caspase-3. Since p27 is a key regulator of G2/M phase arrest and apoptosis $(28,29)$, inhibition of HER2/neu is a key initial mechanism for the apop- totic effect elicited by RL71 in SKBr3 cells. RL71 was more potent than other curcumin analogs at downregulating the expression of HER2/neu, as $4 \mu \mathrm{M}$ concentrations of RL90 and RL91 and $10 \mu \mathrm{M}$ concentrations of and FLLL11 and FLLL12, were required to elicit a similar effect (25). This confirms that RL71 is a lead drug candidate for ER-negative/HER2-positive breast cancer.

MAPK signaling which includes activation of JNK and p38 has been shown to be involved in the regulation of the cell cycle and induction of apoptosis in breast cancer cells (30). Various cytotoxic agents induce apoptotic cell death via activation of MAPK signaling and induction of caspase-3 (31-33). Our studies showed that RL71 treatment induced JNK1/2 and p38 MAPK in MDA-MB-231 and MDA-MB-468 cells. Anticancer agents such as curcumin, which causes activation of $\mathrm{p} 38, \mathrm{JNK} 1 / 2$ and caspase-3, also induce similar apoptotic events $(34,35)$. The MAPK pathway may also upregulate cell cycle regulatory protein, p27 in breast cancer cells (36). Our results demonstrated that in MDA-MB-468 RL71 enhanced the expression of p27 which would contribute to the observed $\mathrm{G} 2 / \mathrm{M}$ cell cycle arrest.

We further studied the effect of RL71 on the PI3K/Akt/ mTOR pathway. Akt is an important oncoprotein which is constitutively active in breast cancer cells and has been implicated in a myriad of regulatory mechanisms involving protein synthesis, cell cycle progression and inhibition of apoptosis $(37,38)$. Our results showed that RL71 decreased the phosphorylation of Akt on Ser-473 in a cell line and time-dependent manner. Specifically, in MDA-MB-468 cells, RL71 decreased Akt phosphorylation fully whereas in MDA-MB-231 cells the phosphorylation of Akt was partially decreased. However, RL71 was more potent than the analogs RL90 and RL91, which did not decrease the ratio of pAkt/Akt at concentrations of $4 \mu \mathrm{M}$ (25). The decreased activity of Akt led to decreased activation of its substrate mTOR in MDA-MB-468 cells. In contrast, in MDA-MB-231 cells there was no change in the expression of mTOR but the expression of 4-EBP1 which is downstream of mTOR was fully downregulated. RL71 failed to alter the expression of PI3K (data not shown) and this suggests that RL71 directly targets downstream events of PI3K/Akt signaling in MDA-MB-231 cells and increased phosphorylation of Akt could be due to a feedback loop mechanism.

Akt contributes to the activity of NF- $\mathrm{kB}$ by controling its translocation to the nucleus (39) and a decrease in Akt activity may affect the stability and level of NF- $\kappa B$ (40). NF- $\mathrm{kB}$ belongs to a family of transcription factors which has been associated with inhibition of apoptosis by promoting the expression of anti-apoptotic proteins such as Bcl-xL, c-Myb and caspase inhibitors $(41,42)$. RL71 downregulated the expression of NF- $\mathrm{KB}$ in MDA-MB-231 cells. However, higher concentrations were required to downregulate NF- $\mathrm{KB}$ in MDA-MB-468 cells (data not shown). Curcumin has also been shown to interfere with the functions of Akt and MAPKs and further inhibit its downstream target NF- $\mathrm{KB}(43,44)$ and thus RL71 retains many of the same actions as curcumin.

To determine if RL71 exhibited anti-angiogenic properties, we examined the effect of RL71 in multiple in vitro angiogenesis assays. Angiogenesis is essential for tumor growth and metastasis and inhibition of metastasis is critical as it is cancer spread that leads to mortality. Importantly, RL71 had an inhibitory effect on endothelial cell migration and tube formation 
demonstrating an anti-angiogenic effect from this compound. The mechanism of this effect will be studied further using in vivo live imaging.

RL71 showed potent cytotoxicity in ER-negative breast cancercells compared to other cyclohexanone curcumin analogs $(21,23)$. Moreover, it had superior cytotoxicity compared with other curcumin analogs such as 3,5-bis(flurobenzylidene) piperidin-4-one (EF24) (45) 5-bis (4-hydroxy-3-methoxybenzylidnen)-N-methyl-4-piperidone (PAC) (46) and GO-Y030 (47) in MDA-MB-231 cells. Specifically IC $_{50}$ values of $1.2,1$ and $0.3 \mu \mathrm{M}$ were reported for EF24, GO-Y030 and RL71, respectively $(23,45,47)$. While EF24 induced G2/M phase arrest and apoptosis in MDA-MB-231 cells (22) and inhibited the $\mathrm{NF}-\kappa \mathrm{B}$ pathway in a $\mathrm{TNF} \alpha$-dependent manner (45), it has not been examined in other breast cancer cells. Additionally, RL71 has a stronger ability to induce apoptosis compared to the analog 4-hydroxy-3-methoxybenzoic acid methyl ester (HM-BME), where $25 \mu \mathrm{M}$ was required to cause $37 \%$ of LNCaP prostate cancer cells to undergo apoptosis after $24 \mathrm{~h}$ (48). The curcumin analogs FLLL11 and FLLL12 were equally potent as RL71 in MDA-MB-468 cells with similar $\mathrm{IC}_{50}$ values $(0.3 \mu \mathrm{M})$. However, this did not translate to other breast cancer cell types as these analogs had $\mathrm{IC}_{50 \mathrm{~s}}$ of $2-5 \mu \mathrm{M}$ in MDA-MB-231 and SkBr3 cells (42). These analogs also downregulated Akt phosphorylation and HER2/neu expression in SKBr3 breast cancer cells but at concentrations of $10 \mu \mathrm{M}$, 10-fold greater than RL71 (49). While other curcumin analogs appear to have a similar mechanism of action as RL71, RL71 is more potent as all of its anti-cancer actions were elicited at concentrations of $1 \mu \mathrm{M}$ or less. Importantly RL71 is orally available following a single oral dose of $8.5 \mathrm{mg} / \mathrm{kg}$ and this is a significant improvement on both curcumin (50) and other first generation analogs (19).

In summary, we showed that RL71 causes cell cycle arrest and induces apoptosis in ER-negative breast cancer cells and also modulates a variety of signaling pathways that culminate in potent cytotoxicity. Specifically, inhibition of Akt pathway and the activation of $\mathrm{p} 38 / \mathrm{JNK}$ pathway may contribute to the anti-cancer activity of RL71 in TNBC cells, while inhibition of HER2/neu and induction of p27 are key mechanisms in SKBr3 cells. Thus, RL71 shows potential as a new drug therapy for ER-negative/Her-2-positive breast cancer. Therefore, RL71 is a novel 2nd generation curcumin derivative that warrants further investigation as a potential therapy for ER-negative breast cancer.

\section{Acknowledgements}

This study was supported by a grant from the Breast Cancer Research Trust (RJR) and a University of Otago postgraduate scholarship (B.Y.).

\section{References}

1. Parl FF, Schmidt BP, Dupont WD and Wagner RK: Prognostic significance of estrogen receptor status in breast cancer in relation to tumor stage, axillary node metastasis, and histopathologic grading. Cancer 54: 2237-2242, 1984.

2. Doane AS, Danso M, Lal P, Donaton M, Zhang L, Hudis C and Gerald WL: An estrogen receptor-negative breast cancer subset characterized by a hormonally regulated transcriptional program and response to androgen. Oncogene 25: 3994-4008, 2006.
3. Carey LA, Dees EC, Sawyer L, et al: The triple negative paradox: primary tumor chemosensitivity of breast cancer subtypes. Clin Cancer Res 13: 2329-2334, 2007.

4. Sorlie T, Perou CM, Tibshirani R, et al: Gene expression patterns of breast carcinomas distinguish tumor subclasses with clinical implications. Proc Natl Acad Sci USA 98: 10869-10874, 2001.

5. Kaplan HG and Malmgren JA: Impact of triple negative phenotype on breast cancer prognosis. Breast J 14: 456-463, 2008.

6. Anand P, Thomas Sherin G, Kunnumakkara Ajaikumar B, et al: Biological activities of curcumin and its analogues (Congeners) made by man and Mother Nature. Biochem Pharmacol 76: 1590-1611, 2008.

7. Cheng A-L, Hsu C-H, Lin J-K, et al: Phase I clinical trial of curcumin, a chemopreventive agent, in patients with high-risk or pre-malignant lesions. Anticancer Res 21: 2895-2900, 2001.

8. Inano $\mathrm{H}$, Onoda $\mathrm{M}$, Inafuku $\mathrm{N}$, et al: Chemoprevention by curcumin during the promotion stage of tumorigenesis of mammary gland in rats irradiated with gamma-rays. Carcinogenesis 20: 1011-1018, 1999.

9. Pereira MA, Grubbs CJ, Barnes LH, et al: Effects of the phytochemicals, curcumin and quercetin, upon azoxymethane-induced colon cancer and 7,12-dimethylbenz[a]anthracene-induced mammary cancer in rats. Carcinogenesis 17: 1305-1311, 1996.

10. Schaaf C, Shan B, Buchfelder M, et al: Curcumin acts as antitumorigenic and hormone-suppressive agent in murine and human pituitary tumour cells in vitro and in vivo. Endocr Relat Cancer 16: 1339-1350, 2009.

11. Singletary K, MacDonald C, Wallig M and Fisher C: Inhibition of 7,12-dimethylbenz[a]anthracene (DMBA)-induced mammary tumorigenesis and DMBA-DNA adduct formation by curcumin. Cancer Lett 103: 137-141, 1996.

12. Chiu T-L and Su C-C: Curcumin inhibits proliferation and migration by increasing the Bax to Bcl-2 ratio and decreasing NF-кBp65 expression in breast cancer MDA-MB-231 cells. Int J Mol Med 23: 469-475, 2009.

13. Kang HJ, Lee SH, Price JE and Kim LS: Curcumin suppresses the paclitaxel-induced nuclear factor- $\kappa \mathrm{B}$ in breast cancer cells and potentiates the growth inhibitory effect of paclitaxel in a breast cancer nude mice model. Breast J 15: 223-229, 2009.

14. Liu Q, Loo WTY, Sze SCW and Tong Y: Curcumin inhibits cell proliferation of MDA-MB-231 and BT-483 breast cancer cells mediated by down-regulation of $\mathrm{NF \kappa B}$, cyclinD and MMP-1 transcription. Phytomed 16: 916-922, 2009.

15. Prasad CP, Rath G, Mathur S, Bhatnagar D and Ralhan R: Potent growth suppressive activity of curcumin in human breast cancer cells: Modulation of Wnt/beta-catenin signaling. Chem Biol Interact 181: 263-271, 2009.

16. Rowe DL, Ozbay T, O'Regan RM and Nahta R: Modulation of the BRCA1 protein and induction of apoptosis in triple negative breast cancer cell lines by the polyphenolic compound curcumin. Breast Cancer Basic Clin Res 3: 61-75, 2009.

17. Somers-Edgar TJ, Scandlyn MJ, Stuart EC, Le Nedelec MJ, Valentine SP and Rosengren RJ: The combination of epigallocatechin gallate and curcumin suppresses ERalpha-breast cancer cell growth in vitro and in vivo. Int J Cancer 122: 19661971, 2008

18. Wu X and Wu K: Antiproliferative effect of curcumin on human breast cancer of MCF-7 cells. Di-San Junyi Daxue Xuebao 28: 1870-1872, 2006.

19. Liang G, Shao L, Wang Y, et al: Exploration and synthesis of curcumin analogues with improved structural stability both in vitro and in vivo as cytotoxic agents. Bioorg Med Chem 17: 2623-2631, 2009.

20. Markaverich BM, Schauweker TH, Gregory RR, Varma M, Kittrell FS, Medina D and Varma RS: Nuclear type II sites and malignant cell proliferation: inhibition by 2,6-bis-benzylidenecyclohexanones. Cancer Res 52: 2482-2488, 1992.

21. Adams BK, Ferstl EM, Davis MC, et al: Synthesis and biological evaluation of novel curcumin analogs as anti-cancer and antiangiogenesis agents. Bioorg Med Chem 12: 3871-3883, 2004.

22. Adams Brian K, Cai J, Armstrong J, et al: EF24, a novel synthetic curcumin analog, induces apoptosis in cancer cells via a redoxdependent mechanism. Anticancer Drugs 16: 263-275, 2005.

23. Yadav B, Taurin S, Rosengren RJ, Schumacher M, Diederich M, Somers-Edgar TJ and Larsen L: Synthesis and cytotoxic potential of heterocyclic cyclohexanone analogues of curcumin. Bioorg Med Chem 18: 6701-6707, 2010.

24. Skehan P, Storeng R, Scudiero D, et al: New colorimetric cytotoxicity assay for anti-cancer drug screening. J Natl Cancer Inst 82: $1107-1112,1990$. 
25. Somers-Edgar TJ, Taurin S, Larsen L, Chandramouli A Nelson MA and Rosengren RJ: Mechanisms for the activity of heterocyclic cyclohexanone curcumin derivatives in estrogen receptor negative human breast cancer cell lines. Invest New Drugs 29: 87-97, 2011.

26. Stuart EC and Rosengren RJ: The combination of raloxifene and epigallocatechin gallate suppresses growth and induces apoptosis in MDA-MB-231 cells. Life Sci 82: 943-948, 2008.

27. Wang SC and Hung MC: HER 2 overexpression and cancer targeting. Semin Oncol 28: 115-124, 2001.

28. Hsieh WT, Huang KY, Lin HY and Chung JG: Physalis angulata induced G2/M phase arrest in human breast cancer cells. Food Chem Toxicol 44: 974-983, 2006.

29. Hsu JD, Kao SH, Ou TT, Chen YJ, Li YJ and Wang CJ: Gallic acid induces $\mathrm{G} 2 / \mathrm{M}$ phase arrest of breast cancer cell MCF-7 through stabilization of p27(Kip1) attributed to disruption of p27(Kip1)/Skp2 complex. J Agric Food Chem 59: 1996-2003, 2011.

30. Santen RJ, Song RX, McPherson R, Kumar R, Adam L, Jeng MH and Yue W: The role of mitogen-activated protein (MAP) kinase in breast cancer. J Steroid Biochem Mol Biol 80: 239-256, 2002.

31. Wada T and Penninger JM: Mitogen-activated protein kinases in apoptosis regulation. Oncogene 23: 2838-2849, 2004.

32. Liu B, Han M, Sun RH, Wang JJ, Zhang YP, Zhang DQ and Wen JK: ABL-N-induced apoptosis in human breast cancer cells is partially mediated by c-Jun NH2-terminal kinase activation. Breast Cancer Res 12: R9, 2010.

33. Kuo PL, Chen CY and Hsu YL: Isoobtusilactone a induces cell cycle arrest and apoptosis through reactive oxygen species/ apoptosis signal-regulating kinase 1 signaling pathway in human breast cancer cells. Cancer Res 67: 7406-7420, 2007.

34. Collett GP and Campbell FC: Curcumin induces c-jun N-terminal kinase-dependent apoptosis in HCT116 human colon cancer cells. Carcinogenesis 25: 2183-2189, 2004.

35. Weir NM, Selvendiran K, Kutala VK, et al: Curcumin induces $\mathrm{G} 2 / \mathrm{M}$ arrest and apoptosis in cisplatin-resistant human ovarian cancer cells by modulating Akt and p38 MAPK. Cancer Biol Ther 6: 178-184, 2007.

36. Eto I: Nutritional and chemopreventive anti-cancer agents up-regulate expression of p27Kip1, a cyclin-dependent kinase inhibitor, in mouse JB6 epidermal and human MCF7, MDA-MB321 and AU565 breast cancer cells. Cancer Cell Int 6: 20, 2006.

37. Dillon RL, White DE and Muller WJ: The phosphatidyl inositol 3-kinase signaling network: implications for human breast cancer. Oncogene 26: 1338-1345, 2007.

38. Vivanco I and Sawyers CL: The phosphatidylinositol 3-kinase AKT pathway in human cancer. Nat Rev Cancer 2: 489-501, 2002 .
39. Burow ME, Weldon CB, Melnik LI, Duong BN, CollinsBurow BM, Beckman BS and McLachlan JA: PI3-K/AKT regulation of NF-kappaB signaling events in suppression of TNF-induced apoptosis. Biochem Biophys Res Commun 271: 342-345, 2000.

40. Gong L, Li Y, Nedeljkovic-Kurepa A and Sarkar FH: Inactivation of NF-kappaB by genistein is mediated via Akt signaling pathway in breast cancer cells. Oncogene 22: 4702-4709, 2003.

41. Barkett $M$ and Gilmore TD: Control of apoptosis by Rel/ NF-kappaB transcription factors. Oncogene 18: 6910-6924, 1999.

42. Lauder A, Castellanos A and Weston K: c-Myb transcription is activated by protein kinase $\mathrm{B}$ (PKB) following interleukin 2 stimulation of $\mathrm{T}$ cells and is required for $\mathrm{PKB}$-mediated protection from apoptosis. Mol Cell Biol 21: 5797-5805, 2001.

43. Shehzad A, Wahid F and Lee YS: Curcumin in cancer chemoprevention: molecular targets, pharmacokinetics, bioavailability, and clinical trials. Arch Pharm 343: 489-499, 2010.

44. Dhandapani KM, Mahesh VB and Brann DW: Curcumin suppresses growth and chemoresistance of human glioblastoma cells via AP-1 and NFkappaB transcription factors. J Neurochem 102: 522-538, 2007.

45. Kasinski AL, Du Y, Thomas SL, et al: Inhibition of IkappaB kinase-nuclear factor-kappaB signaling pathway by 3,5-bis(2flurobenzylidene)piperidin-4-one (EF24), a novel monoketone analog of curcumin. Mol Pharmacol 74: 654-661, 2008.

46. Al-Hujaily EM, Mohamed AG, Al-Sharif I, et al: PAC, a novel curcumin analogue, has anti-breast cancer properties with higher efficiency on Er-negative cells. Breast Cancer Res Treat 128: 97-107, 2010.

47. Hutzen B, Friedman L, Sobo M, et al: Curcumin analogue GO-Y030 inhibits STAT3 activity and cell growth in breast and pancreatic carcinomas. Int J Oncol 35: 867-872, 2009.

48. Kumar AP, Garcia GE, Ghosh R, Rajnarayanan RV, Alworth WL and Slaga TJ: 4-Hydroxy-3-methoxybenzoic acid methyl ester: a curcumin derivative targets Akt/NF kappa B cell survival signaling pathway: potential for prostate cancer management. Neoplasia 5: 255-266, 2003.

49. Lin L, Hutzen B, Ball S, et al: New curcumin analogues exhibit enhanced growth-suppressive activity and inhibit AKT and signal transducer and activator of transcription 3 phosphorylation in breast and prostate cancer cells. Cancer Sci 100: 1719-1727, 2009.

50. Anand P, Kunnumakkara AB, Newman RA and Aggarwal BB: Bioavailability of curcumin: problems and promises. Mol Pharm 4: 807-818, 2007. 